\title{
Effect of polymers on crystallization in glass-forming molecular liquids: Equal suppression of nucleation and growth and master curve for prediction
}

\author{
Xin Yao ${ }^{1}$, Chengbin Huang ${ }^{1}$, Emily G. Benson ${ }^{1,2}$, Chenyang Shi ${ }^{3}$, Geoff G. Z. Zhang ${ }^{3, *}$, \\ Lian $\mathrm{Yu}^{1,2, *}$ \\ ${ }^{1}$ School of Pharmacy, University of Wisconsin-Madison, Madison, WI, 53705, USA \\ ${ }^{2}$ Department of Chemistry, University of Wisconsin-Madison, Madison, WI, 53705, USA \\ ${ }^{3}$ Drug Product Development, Research and Development, AbbVie Inc., North Chicago, IL,
} 60064, USA

\section{Supporting Information}

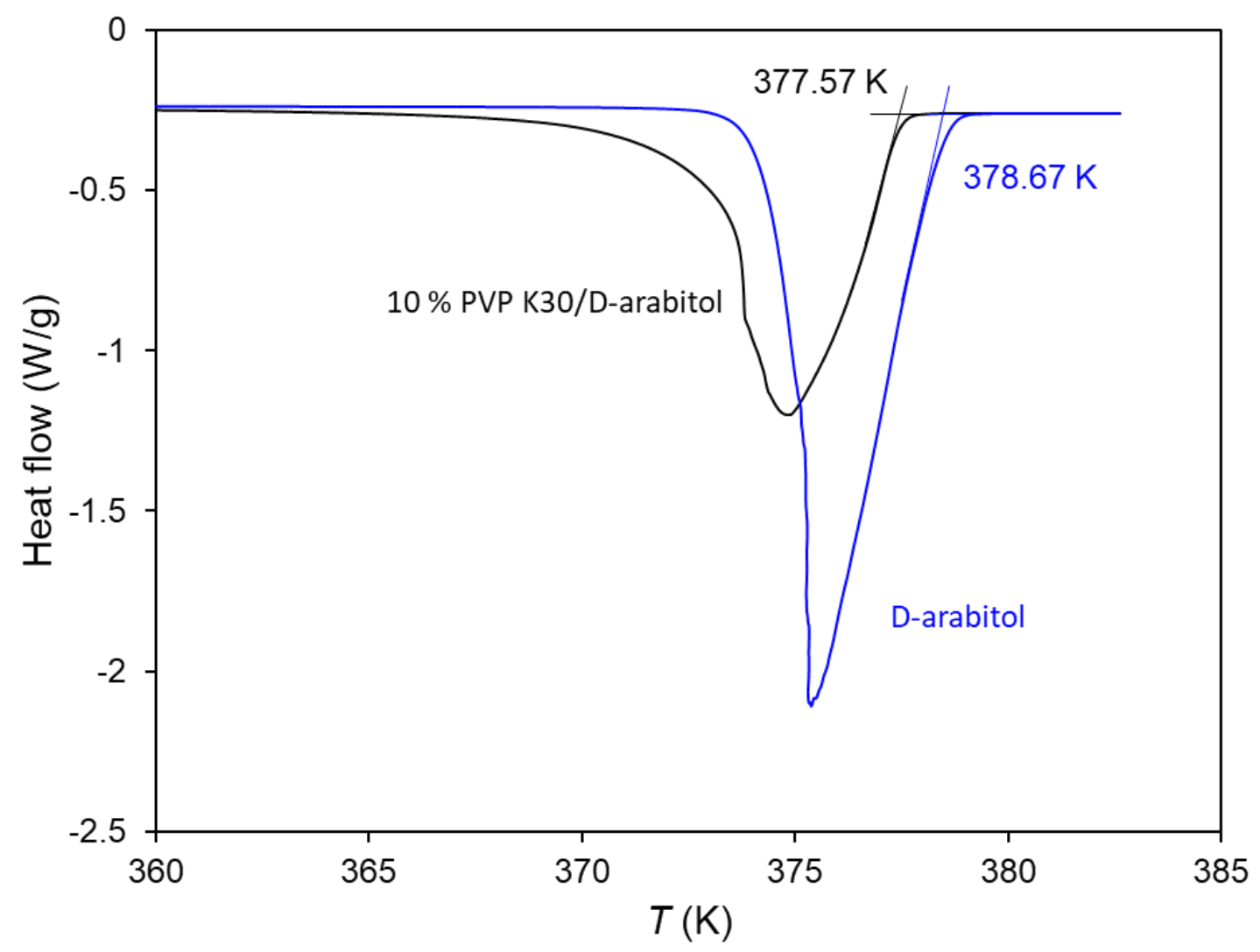

Figure S1. Effect of 10 wt \% PVP K30 on the melting point of D-arabitol Form I. Each DSC trace was recorded at a heating rate of $1 \mathrm{~K} / \mathrm{min}$ in the temperature range shown. The endpoint of melting is depressed by approximately $1 \mathrm{~K}$ by $10 \mathrm{wt} \%$ PVP K30. 


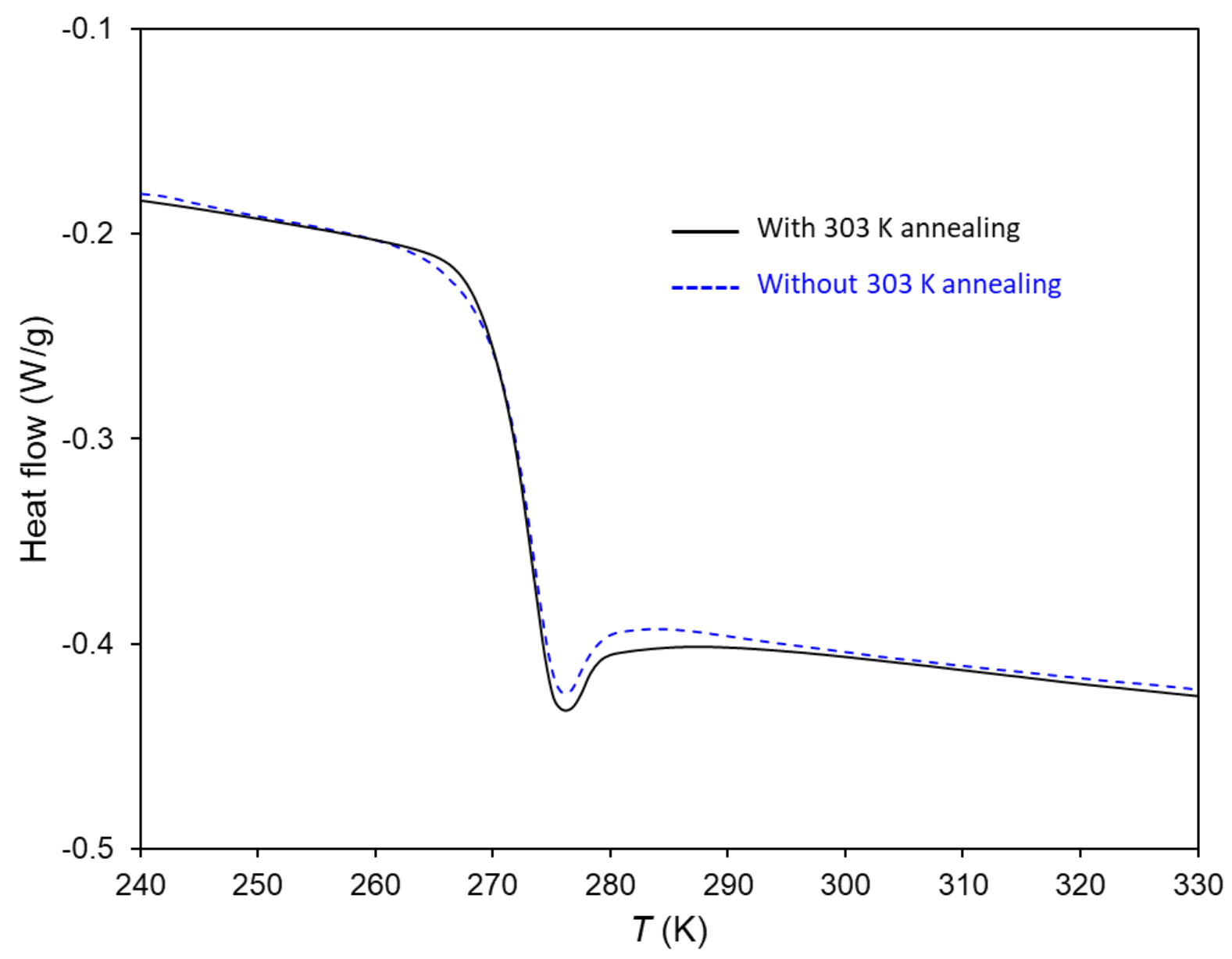

Figure S2. Effect of annealing on the glass transition temperature $T_{\mathrm{g}}$ of D-sorbitol containing 10 wt \% PVP K30. Both DSC traces were recorded during heating at $10 \mathrm{~K} / \mathrm{min}$, one for the freshly prepared material and the other after annealing at $303 \mathrm{~K}$ for $120 \mathrm{~min}$. There is no significant change of $T_{\mathrm{g}}$ as a result of annealing, indicating no phase separation. 
a D-arabitol
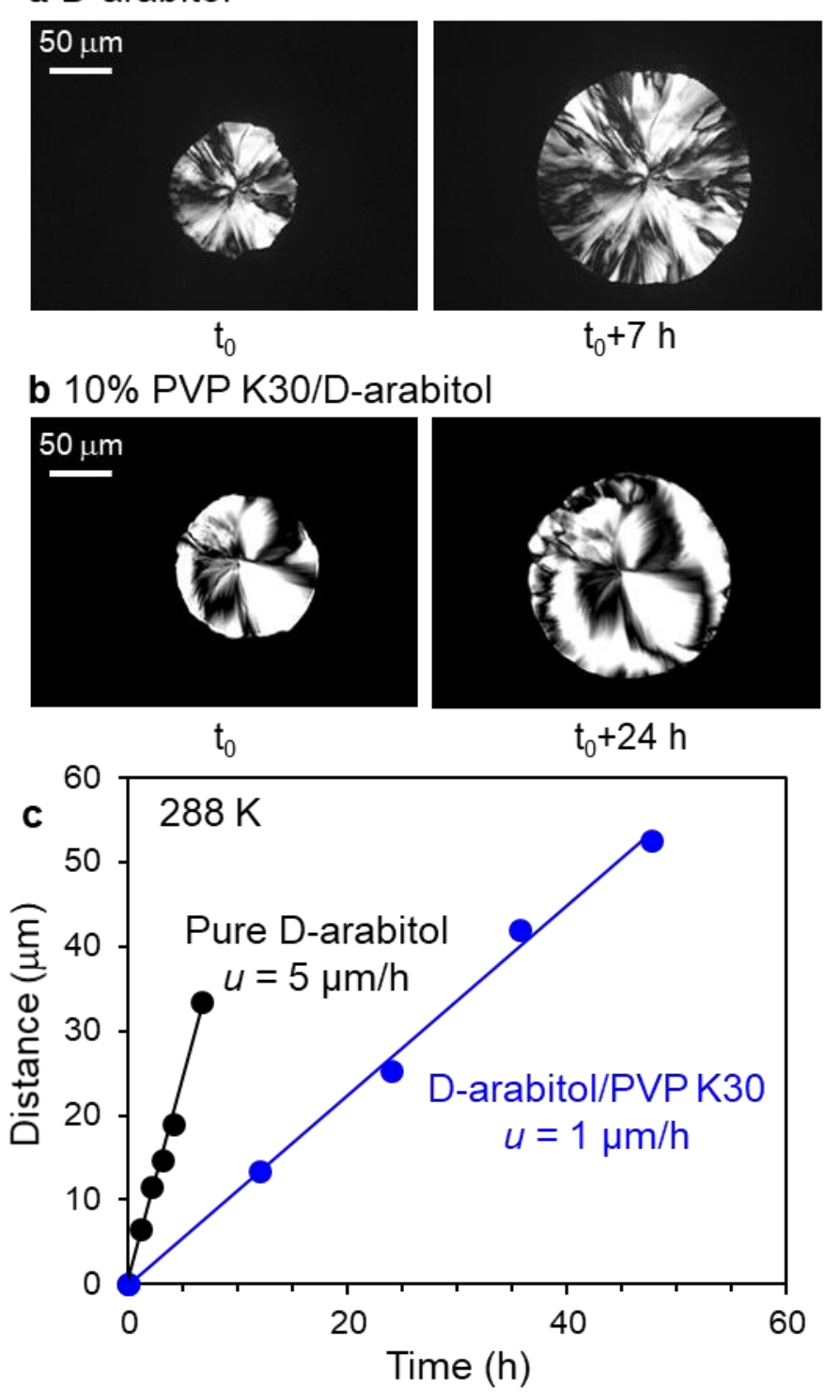

Figure S3. The measurement of crystal growth rate in D-arabitol and D-arabitol containing 10\% PVP K30 at $288 \mathrm{~K}$. (a) and (b): Light microscopy images of growing crystals. (c) Distance of growth vs. time at $288 \mathrm{~K}$. The slope of each plot is the crystal growth rate. 